\title{
Thermoelectric Properties of Perovskite-Type Oxide Ca-Mn-O System in Relation to A-Site Vacancies
}

\author{
Hiroshi Kawakami ${ }^{1, *}$, Miwa Saito ${ }^{2}$, Hironao Takemoto ${ }^{2}$, Hiroshi Yamamura ${ }^{2}$, \\ Yukihiro Isoda ${ }^{1}$ and Yoshikazu Shinohara ${ }^{1}$ \\ ${ }^{1}$ Eco-energy Group, National Institute for Materials Science, Tsukuba 305-0047, Japan \\ ${ }^{2}$ Department of Material and Life Chemistry, Faculty of Engineering, Kanagawa University, Yokohama 221-8686, Japan
}

\begin{abstract}
The orthorhombic perovskite-type oxide systems, $\mathrm{Ca}_{1-x} \mathrm{Nd}_{x} \mathrm{MnO}_{3}$ and $\mathrm{Ca}_{1-x} \mathrm{Nd}_{2 x / 3} \square_{x / 3} \mathrm{MnO}_{3}$ ( $\square$ indicates A-site vacancy) were synthesized by a standard ceramic technique. Thermoelectric properties such as Seebeck coefficient $(S)$, electrical conductivity $(\sigma)$ and thermal conductivity $(\kappa)$ were evaluated as functions of temperature $(T)$ and composition $(x)$. The electrical conductivity increased and the absolute Seebeck coefficient decreased with increased composition, in both the systems. Jonker plots revealed that the insertion of A-site vacancies improved the carrier mobility of Perovskite-type oxides without resulting in a change in their carrier concentration. This insertion induced low thermal conductivity owing to the atomic unbalance of the crystal structure. A-site vacancies are key factors in obtaining higher electrical conductivity and lower thermal conductivity. [doi:10.2320/matertrans.M2013121]
\end{abstract}

(Received March 26, 2013; Accepted June 4, 2013; Published July 26, 2013)

Keywords: $\mathrm{CaMnO}_{3}$, Perovskite, thermoelectric properties, A-site vacancy, lattice defect

\section{Introduction}

In the recent trend of energy supply, thermal and nuclear power generation systems are typical power generation systems that harness thermal energy. These power generation systems convert thermal energy into kinetic energy, and then convert kinetic energy into electric energy, and in this process, most of the thermal energy is lost as waste heat. In contrast, thermoelectric power generation systems directly convert thermal energy into electric energy by utilizing energy garnered by the temperature differential between the source and the sink. In this type of system, waste heat is available for re-use. High-temperature thermoelectric materials need high thermal and chemical stability for long time use at high temperatures and in various atmospheres. Metal oxides have both high thermal and high chemical stability and are potentially suitable materials for hightemperature thermoelectric applications. ${ }^{1-3)}$ Low density of the metal oxides is also attractive when we evaluate power density.

The performance of thermoelectric materials can be assessed in terms of the figure of merit $Z$ given by the following equation:

$$
Z=S^{2} \sigma / \kappa,
$$

where $S, \sigma$ and $\kappa$ are the Seebeck coefficient, the electrical conductivity and the thermal conductivity, respectively. $S^{2} \sigma$ is called the power factor.

There are relatively few n-type oxide materials. Among the n-type oxide materials, $\mathrm{CaMnO}_{3}$ based materials with Perovskite-type structure are the most promising materials as possible n-type oxide thermoelectric material. For polycrystalline $\mathrm{CaMnO}_{3}$ based materials, Ohtaki et al. ${ }^{4)}$ and D. Flahaut et al. ${ }^{5)}$ reported $Z$ values of $0.14 \times 10^{-3} \mathrm{~K}^{-1}$ $(Z T=0.16$ at $T=1173 \mathrm{~K})$ and $0.16 \times 10^{-3} \mathrm{~K}^{-1}(Z T=0.16$ at $T=1000 \mathrm{~K})$, respectively. For enhancing the figure of

*Corresponding author, E-mail: KAWAKAMI.Hiroshi@nims.go.jp merit, the thermal conductivity should be further decreased without decreasing the electrical conductivity. ${ }^{6)}$ To decrease the thermal conductivity, the crystallo-chemical information is important. In previous studies, ${ }^{7,8)}$ we focused on Perovskite-type compounds that have a Ruddlesden-popper structure $^{9)}$ with a general formula of $\mathrm{AO} \cdot n(\mathrm{ABO})_{3}$, or Perovskite structure with A-site vacancies and a general formula of $\mathrm{A}_{1-x} \mathrm{BO}_{3-x}$. The Ruddlesden-popper structure includes rock salt layers (referred to as heat resistance layers (HRL)) that could decrease the thermal conductivity, but they also decrease the electrical conductivity. However, the insertion of A-site vacancies into $\mathrm{Ca}_{1-x} \mathrm{La}_{x} \mathrm{MnO}_{3}$ could improve the figure of merit by decreasing the thermal conductivity and increasing the electrical conductivity. ${ }^{10)}$

The insertion of A-site vacancy in the perovskite-type structures can give particular physical properties. Zonggang et al., reported that a sensor based on $\mathrm{La}_{0.9} \square_{0.1} \mathrm{FeO}_{3}$ showed excellent $\mathrm{CO}$ gas-sensing characteristics ${ }^{11)}$ and Xue Li et al., reported high ionic conductivity in $\left(\mathrm{La}_{0.7} \mathrm{Sr}_{0.3}\right)_{0.93} \mathrm{TiO}_{3-\delta}$ sample. $^{12)}$ In addition, Perovskite oxides with A-site vacancies have been reported in many studies of Li-ion conductor. ${ }^{13-15)}$ However, few have reported on the effects of the insertion of A-site vacancies in thermoelectric materials.

In this study, the thermoelectric properties of the systems, $\mathrm{Ca}_{1-x} \mathrm{Nd}_{x} \mathrm{MnO}_{3}$ and $\mathrm{Ca}_{1-x} \mathrm{Nd}_{2 x / 3} \square_{x / 3} \mathrm{MnO}_{3}$ having A-site vacancies for electroneutrality in the nominal composition were investigated in order to clarify the crystallo-chemical factors that affect the thermoelectric properties.

\section{Experimental}

All of the samples were prepared by a solid state reaction. $\mathrm{CaCO}_{3}$ (99.99\%, Kojundo chemical), $\mathrm{Nd}_{2} \mathrm{O}_{3}$ (99.9\%, Kojundo chemical Lab. Co., Ltd.) and $\mathrm{MnO}_{2}$ (99.99\%, Kojundo chemical Lab. Co., Ltd.) were used as starting materials. Weighed powders were mixed for $24 \mathrm{~h}$ using a ball mill and then calcined at $1273 \mathrm{~K}$ for $10 \mathrm{~h}$ in air. The powders were sieved to obtain a nominal size of less than $53 \mu \mathrm{m}$. The 

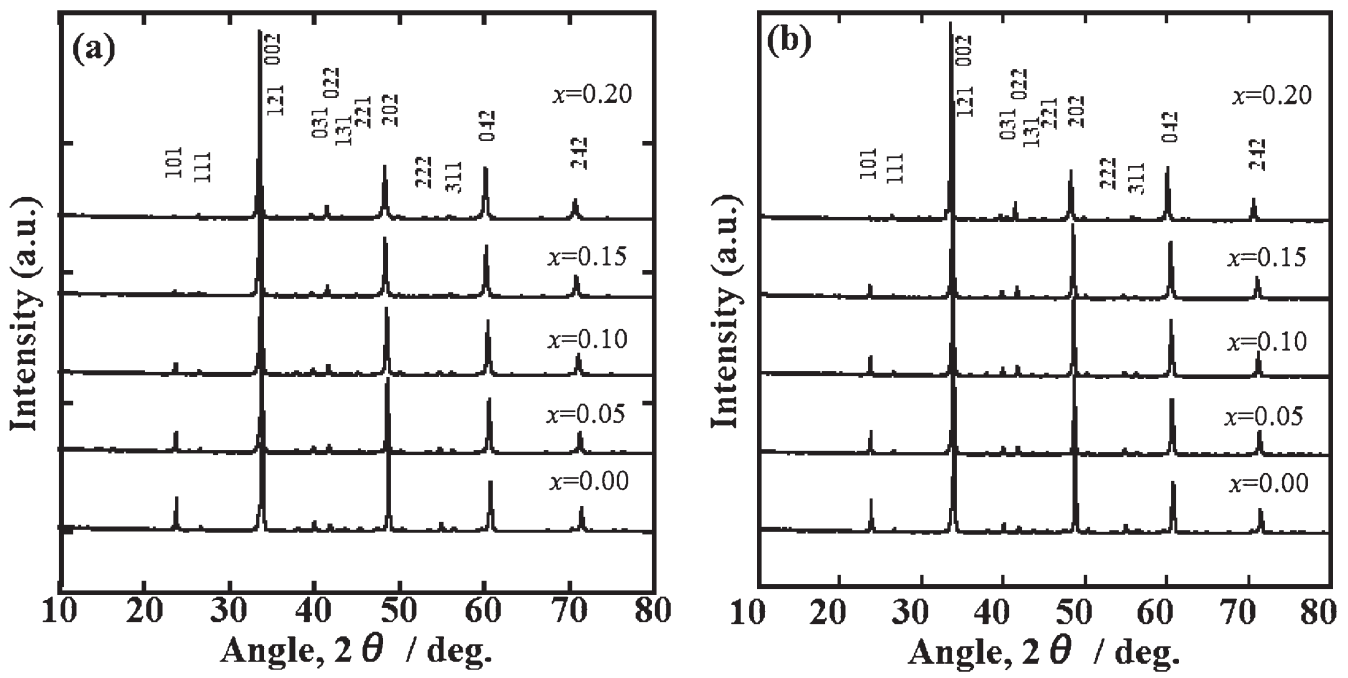

Fig. 1 XRD patterns of (a) $\mathrm{Ca}_{1-x} \mathrm{Nd}_{x} \mathrm{MnO}_{3}$ and (b) $\mathrm{Ca}_{1-x} \mathrm{Nd}_{2 x / 3} \square_{x / 3} \mathrm{MnO}_{3}$.
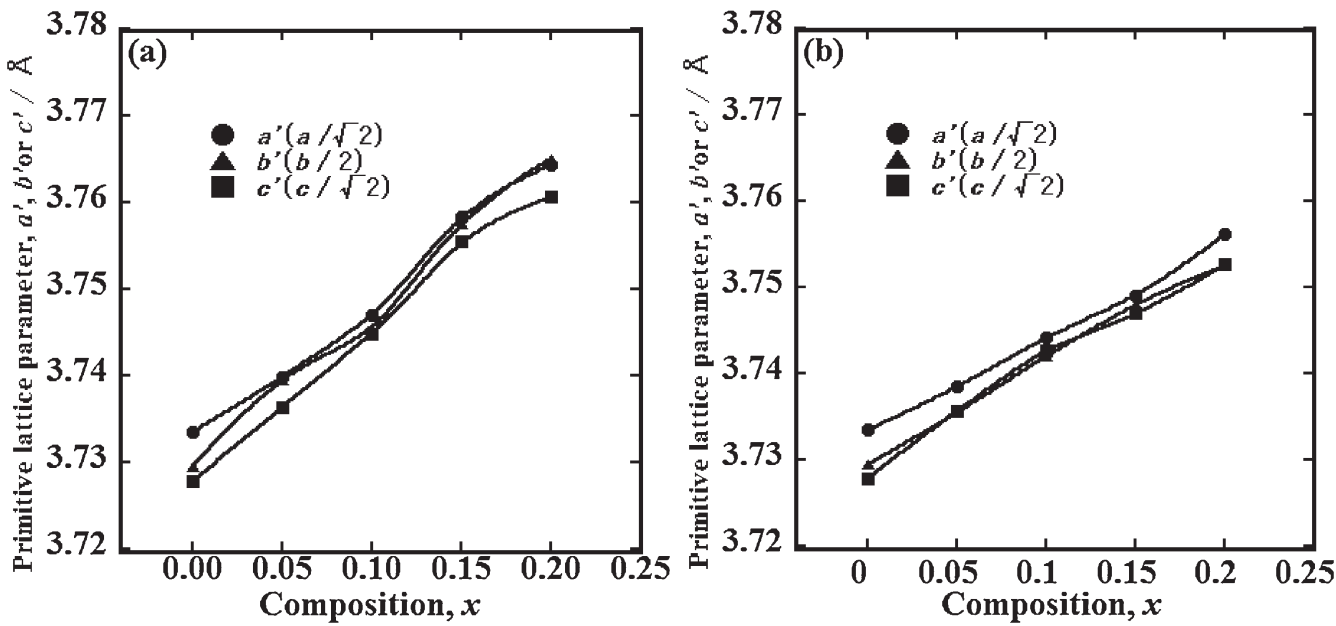

Fig. 2 Primitive lattice parameter of (a) $\mathrm{Ca}_{1-x} \mathrm{Nd}_{x} \mathrm{MnO}_{3}$ and (b) $\mathrm{Ca}_{1-x} \mathrm{Nd}_{2 x / 3} \square_{x / 3} \mathrm{MnO}_{3}$.

mixed powders were pressed into a rectangular shape under a pressure of $5 \mathrm{MPa}$ and then subjected to rubber pressing under $196 \mathrm{MPa}$. These samples were sintered in air at $1573 \mathrm{~K}$ for $10 \mathrm{~h}$. The identification of the samples and the determination of lattice parameter were performed by X-ray diffractometry using $\mathrm{Cu} \mathrm{K} \alpha$ radiation at room temperature.

The electrical conductivity and the Seebeck coefficient of the sintered specimens were measured in the temperature range from 873 to $1080 \mathrm{~K}$ using a ZEM-3 apparatus (ULVAC-RIKO, Inc.). The thermal conductivity of the sintered samples were measured by the comparison method at $873 \mathrm{~K}$. Quartz glass $\left(2.2 \mathrm{Wm} \mathrm{K}^{-2}\right.$ at $\left.873 \mathrm{~K}\right)$ was used as the standard sample.

\section{Results and Discussion}

Figures 1(a) and 1(b) show the powder X-ray diffraction patterns for $\mathrm{Ca}_{1-x} \mathrm{Nd}_{x} \mathrm{MnO}_{3}(0 \leqq x \leqq 0.2)$ and $\mathrm{Ca}_{1-x} \mathrm{Nd}_{2 x / 3^{-}}$ $\square_{x / 3} \mathrm{MnO}_{3} \quad(0 \leqq x \leqq 0.2)$, respectively. The powder XRD patterns of $\mathrm{Ca}_{1-x} \mathrm{Nd}_{x} \mathrm{MnO}_{3}(0 \leqq x \leqq 0.15)$ and $\mathrm{Ca}_{1-x} \mathrm{Nd}_{2 x / 3^{-}}$ $\square_{x / 3} \mathrm{MnO}_{3}(0 \leqq x \leqq 0.2)$ were successfully indexed according to the orthorhombic $\mathrm{CaMnO}_{3}$-type structure belonging to the space group Pnma. Figures 2(a) and 2(b) show the primitive lattice parameters $a^{\prime}, b^{\prime}$ and $c^{\prime}$ of $\mathrm{Ca}_{1-x} \mathrm{Nd}_{x} \mathrm{MnO}_{3}$ $(0 \leqq x \leqq 0.2) \quad$ and $\quad \mathrm{Ca}_{1-x} \mathrm{Nd}_{2 x / 3} \square_{x / 3} \mathrm{MnO}_{3} \quad(0 \leqq x \leqq 0.2)$, respectively. The relationship between orthorhombic and primitive Perovskite-type structures for the space group Pnma, can be defined as follows:

$$
\begin{gathered}
a^{\prime} \approx a / \sqrt{2}, \\
b^{\prime} \approx b / 2, \\
c^{\prime} \approx c / \sqrt{2} .
\end{gathered}
$$

For convenience, the orthorhombic and primitive lattice parameters are labeled with $a, b$ and $c$ and with $a^{\prime} b^{\prime}$ and $c^{\prime}$, respectively. The ionic radii of $\mathrm{Ca}^{2+}$ and $\mathrm{Nd}^{3+}$ (coordination number of 12) and $\mathrm{Mn}^{4+}$ and $\mathrm{Mn}^{3+}$ (coordination number of 6) are $0.134,0.127,0.053$ and $0.0645 \mathrm{~nm}$, respectively. ${ }^{16)}$ The primitive-lattice parameters of both systems increase with increasing $x$ although the ionic radius of $\mathrm{Nd}^{3+}$ is smaller than that of $\mathrm{Ca}^{2+}$. Therefore, the increase in the primitivelattice parameters suggests that $\mathrm{Mn}$ valences change from $\mathrm{Mn}^{4+}$ to $\mathrm{Mn}^{3+} . \mathrm{Ca}_{1-x} \mathrm{Nd}_{2 x / 3} \square_{x / 3} \mathrm{MnO}_{3}$ system have same value of $b^{\prime}$ and $c^{\prime}$. The primitive-lattice parameters revealed that the insertion of A-site vacancy induced a crystal structural shift from orthorhombic $\left(a^{\prime}>b^{\prime}>c^{\prime}\right)$ to pseudotetragonal $\left(a^{\prime}>b^{\prime}=c^{\prime}\right)$. 
Table 1 The refined structual parameters for $\mathrm{Ca}_{0.9} \mathrm{Nd}_{0.1} \mathrm{MnO}_{3}(P n m a)$.

\begin{tabular}{|c|c|c|c|c|c|c|c|}
\hline & Atom & Site & $g$ & $x$ & $y$ & $z$ & $\mathrm{~B}\left(\AA^{2}\right)$ \\
\hline $\mathrm{Ca}_{0.9} \mathrm{Nd}_{0.1} \mathrm{MnO}_{3}$ & $\mathrm{Ca} / \mathrm{Nd}$ & $4 c$ & 1.000 & $0.028(1)$ & 0.250 & $-0.006(1)$ & 0.500 \\
\hline$a=5.3036(1) \AA$ & $\mathrm{Mn}$ & $4 b$ & 1.000 & 0.000 & 0.000 & 0.500 & 0.500 \\
\hline$b=7.4894(4) \AA$ & $\mathrm{O}(1)$ & $4 c$ & 1.000 & $0.488(1)$ & 0.250 & $0.066(2)$ & 1.000 \\
\hline \multirow[t]{2}{*}{$c=5.2938(2) \AA$} & $\mathrm{O}(2)$ & $8 \mathrm{~d}$ & 1.000 & $0.288(1)$ & $0.031(1)$ & $-0.287(1)$ & 1.000 \\
\hline & & & $R_{\mathrm{wp}}=9.527 \%$ & $R_{\mathrm{e}}=6.405 \%$ & $R_{\mathrm{B}}=2.944 \%$ & $S=1.488$ & \\
\hline
\end{tabular}

Table 2 The refined structual parameters for $\mathrm{Ca}_{0.85} \mathrm{Nd}_{0.1} \square_{0.05} \mathrm{MnO}_{3}(P n m a)$.

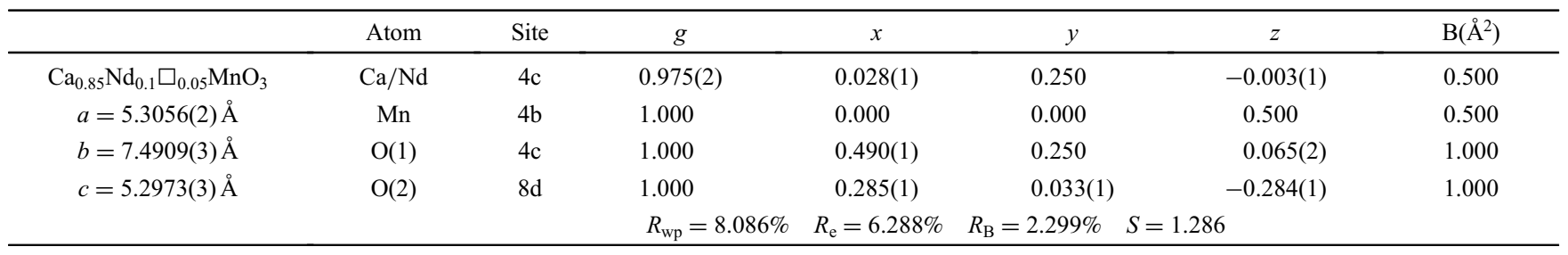

The Rietveld method was employed to confirm existence of an A-site vacancies and structural parameters by using the RIETAN-FP program. ${ }^{17)}$ In this work, we use the same initial atomic positions as those reported by Jorges et al. ${ }^{18)}$ The isotropic atomic displacement parameters (B) in the analysis were fixed, both of $\mathrm{Ca} / \mathrm{Nd}$ site and $\mathrm{Mn}$ site were 0.5 , and both of $O$ (1) site and $O$ (2) site were 1.0, respectively, since B has a strong correlation with occupancy $(g)$. A split pseudo-Voigt function was selected to model the Bragg peak shapes. Tables 1 and 2 present the refined structural parameters for $\mathrm{Ca}_{0.9} \mathrm{Nd}_{0.1} \mathrm{MnO}_{3}$ and $\mathrm{Ca}_{0.85} \mathrm{Nd}_{0.1} \square_{0.05} \mathrm{MnO}_{3}$ in the orthorhombic (Pnma) unit cell. The occupancies ( $g$ ) of both $\mathrm{Ca}_{0.9} \mathrm{Nd}_{0.1} \mathrm{MnO}_{3}$ and $\mathrm{Ca}_{0.85} \mathrm{Nd}_{0.1} \square_{0.05} \mathrm{MnO}_{3}$ are 1.00 and 0.975 , respectively. These results imply that the A-site vacancies exist in the $\mathrm{Ca}_{1-x} \mathrm{Nd}_{2 x / 3} \square_{x / 3} \mathrm{MnO}_{3}$ system.

Thermoelectric properties were investigated as functions of temperature and composition. Figure 3 shows the Seebeck coefficient of both $\mathrm{Ca}_{1-x} \mathrm{Nd}_{x} \mathrm{MnO}_{3}$ and $\mathrm{Ca}_{1-x} \mathrm{Nd}_{2 x / 3} \square_{x / 3-}$ $\mathrm{MnO}_{3}$ systems as a function of the $\mathrm{Nd}$ content at $873 \mathrm{~K}$. Although the nominal composition of the $\mathrm{Ca}_{1-x} \mathrm{Nd}_{2 x / 3} \square_{x / 3^{-}}$ $\mathrm{MnO}_{3}$ system was controlled to maintain the electroneutrality by introducing the A-site vacancy, the absolute Seebeck coefficient of both $\mathrm{Ca}_{1-x} \mathrm{Nd}_{x} \mathrm{MnO}_{3}$ and $\mathrm{Ca}_{1-x} \mathrm{Nd}_{2 x / 3} \square_{x / 3}-$ $\mathrm{MnO}_{3}$ systems decreased with increasing $\mathrm{Nd}$ content and showed same behavior. This relationship between Seebeck coefficient and $\mathrm{Nd}$ content showed that carriers were generated by mainly $\mathrm{Nd}$ substitution. The decrease in the absolute Seebeck coefficient of both $\mathrm{Ca}_{1-x} \mathrm{Nd}_{x} \mathrm{MnO}_{3}$ and $\mathrm{Ca}_{1-x} \mathrm{Nd}_{2 x / 3} \square_{x / 3} \mathrm{MnO}_{3}$ systems likely originates from the increase in carrier concentration owing to the occurrence of $\mathrm{Mn}^{3+}$ when $\mathrm{Nd}^{3+}$ is substituted into a $\mathrm{Ca}^{2+}$ site.

Figures 4(a) and 4(b) show the electrical conductivity of the $\mathrm{Ca}_{1-x} \mathrm{Nd}_{x} \mathrm{MnO}_{3}$ and $\mathrm{Ca}_{1-x} \mathrm{Nd}_{2 x / 3} \square_{x / 3} \mathrm{MnO}_{3}$ systems, respectively, as a function of temperature. The electrical conductivitity of the $\mathrm{Ca}_{1-x} \mathrm{Nd}_{x} \mathrm{MnO}_{3}$ system increased with increasing $x$. The increase in the electrical conductivity of the $\mathrm{Ca}_{1-x} \mathrm{Nd}_{x} \mathrm{MnO}_{3}$ system originates from the increase in carrier concentration owing to the occurrence of $\mathrm{Mn}^{3+}$ by substitution of $\mathrm{Nd}^{3+}$ into a $\mathrm{Ca}^{2+}$ site. The electrical conductivity of the $\mathrm{Ca}_{1-x} \mathrm{Nd}_{2 x / 3} \square_{x / 3} \mathrm{MnO}_{3}$ system is larger

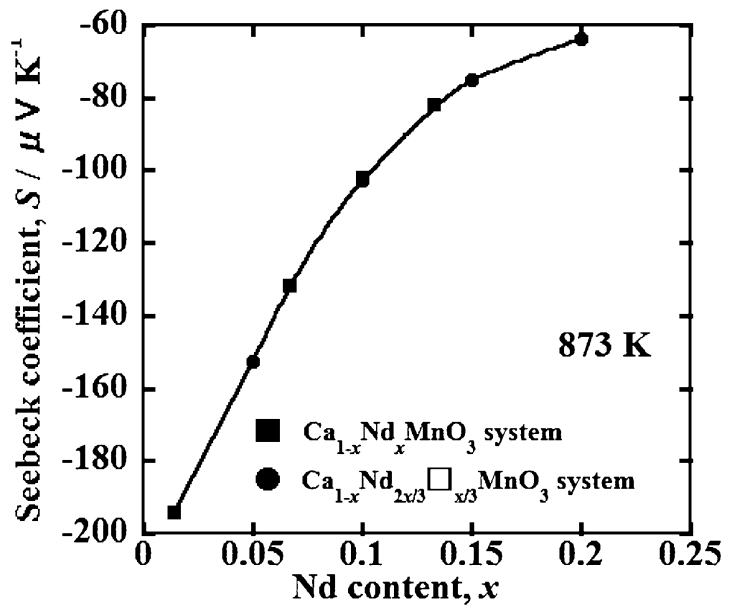

Fig. 3 Seebeck coefficient as a function of $\mathrm{Nd}$ content for $\mathrm{Ca}-\mathrm{Mn}-\mathrm{O}$ systems at $873 \mathrm{~K}$.

than that of the $\mathrm{Ca}_{1-x} \mathrm{Nd}_{x} \mathrm{MnO}_{3}$ system. In order to clarify the relationship between electrical conductivity and Seebeck coefficient, the plots of the $S$ value to $\ln \sigma$ for the same temperature range from 873 to $1073 \mathrm{~K}$, which are called Jonker plots, ${ }^{19,20)}$ are shown in Fig. 5. Figure 5 shows that the both $\mathrm{Ca}_{0.9} \mathrm{Nd}_{0.1} \mathrm{MnO}_{3}$ and $\mathrm{Ca}_{0.85} \mathrm{Nd}_{0.1} \square_{0.05} \mathrm{MnO}_{3}$ have the same Seebeck coefficient and different electrical conductivity. The electrical conductivity is written as

$$
\sigma=n e \mu
$$

where $n, e$ and $\mu$ are the carrier concentration, electron charge and carrier mobility, respectively. Although the carrier concentrations of both $\mathrm{Ca}_{0.9} \mathrm{Nd}_{0.1} \mathrm{MnO}_{3}$ and $\mathrm{Ca}_{0.85^{-}}$ $\mathrm{Nd}_{0.1} \square_{0.05} \mathrm{MnO}_{3}$ are same, the electrical conductivities of $\mathrm{Ca}_{0.85} \mathrm{Nd}_{0.1} \square_{0.05} \mathrm{MnO}_{3}$ are larger than that of $\mathrm{Ca}_{0.9} \mathrm{Nd}_{0.1} \mathrm{MnO}_{3}$ (Fig. 5). Jonker plots revealed that the insertion of A-site vacancies improved the carrier mobility of Perovskite-type oxides without changing the carrier concentration. The increase in carrier mobility likely originates from the change in crystal-symmetry. Furthermore, there may be a change in the conduction pass or in the effective electron mass from the 

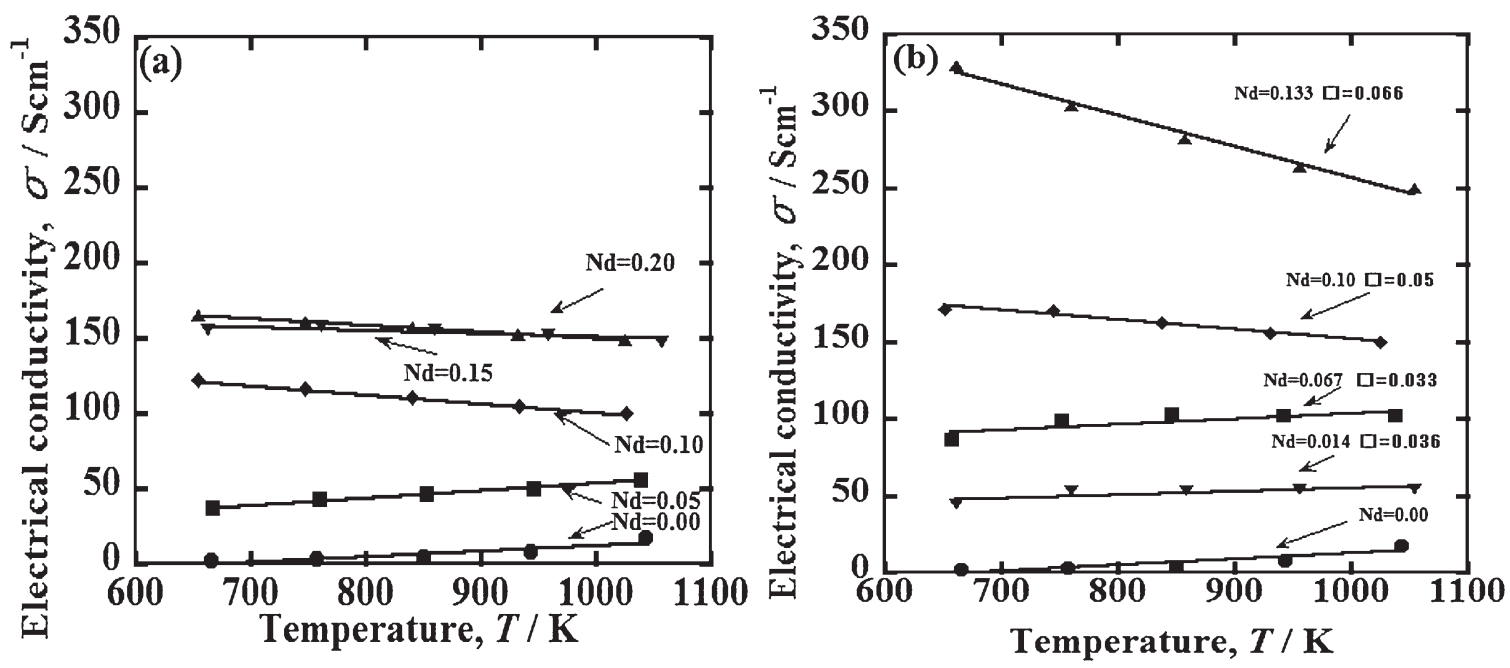

Fig. 4 Electrical conductivity of (a) $\mathrm{Ca}_{1-x} \mathrm{Nd}_{x} \mathrm{MnO}_{3}$ and (b) $\mathrm{Ca}_{1-x} \mathrm{Nd}_{2 x / 3} \square_{x / 3} \mathrm{MnO}_{3}$.

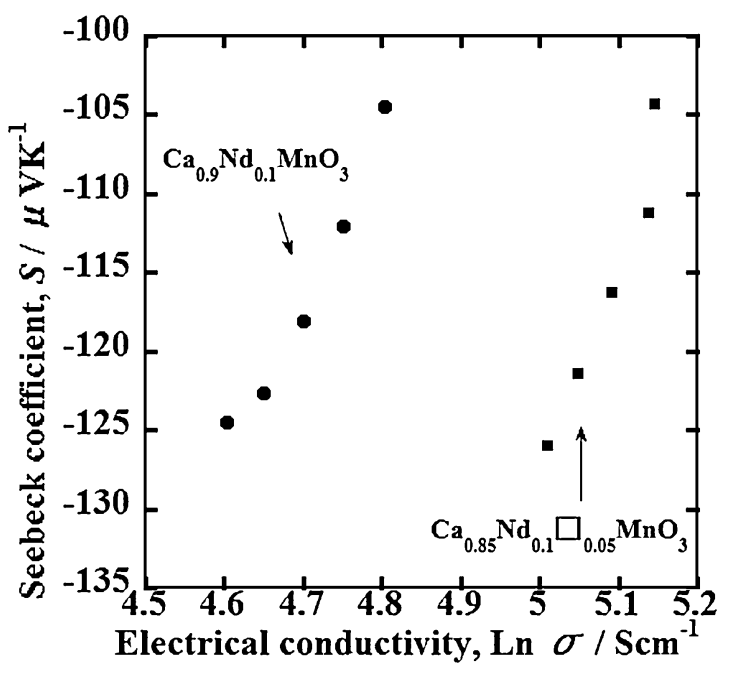

Fig. 5 Jonker plot of $\mathrm{Ca}_{0 .} \mathrm{Ndd}_{0.1} \mathrm{MnO}_{3}$ and $\mathrm{Ca}_{0.85} \mathrm{Nd}_{0.1} \square_{0.05} \mathrm{MnO}_{3}$.

A-site vacancy. In addition, future works are necessary such as the study of quantitative relationship between mobility and content of A-site vacancies.

Figures 6(a) and 6(b) show thermal conductivity $(\kappa)$ of both the $\mathrm{Ca}_{1-x} \mathrm{Nd}_{x} \mathrm{MnO}_{3}$ and $\mathrm{Ca}_{1-x} \mathrm{Nd}_{2 x / 3} \square_{x / 3} \mathrm{MnO}_{3}$ systems at $873 \mathrm{~K}$. The electronic thermal conductivity $\left(\kappa_{\mathrm{e}}\right)$ is given by the following equation:

$$
\kappa_{\mathrm{e}}=L \sigma T
$$

where $L$ represents the Lorenz number $\left(2.45 \times 10^{-8}\right.$ $\left.\mathrm{W} \Omega \mathrm{K}^{-2}\right)$. The lattice thermal conductivity $\left(\kappa_{\mathrm{L}}\right)$ can be given by the following equation:

$$
\kappa_{\mathrm{L}}=\kappa-\kappa_{\mathrm{e}}
$$

Although the value of $\kappa_{\mathrm{e}}$ increased with increasing electrical conductivity, the influence of $\kappa_{\mathrm{e}}$ on the total $\kappa$ is very small, as its value if very small in comparison with the value of $\kappa$. For all samples, the phonon contribution is more important than the electronic contribution, and therefore, the total $\kappa$ is mainly ascribed to the lattice contribution. The thermal conductivities of both systems decreased with increased Nd content. Additionally, the insertion of an A-site vacancy into the $\mathrm{Ca}_{1-x} \mathrm{Nd}_{x} \mathrm{MnO}_{3}$ system further lowered the $\kappa$ for that system. For example, by the insertion of A-site vacancy into the $\mathrm{Ca}_{0.9} \mathrm{Nd}_{0.1} \mathrm{MnO}_{3}, \mathrm{Ca}_{0.85} \mathrm{Nd}_{0.1} \square_{0.05} \mathrm{MnO}_{3}$ reduced $\kappa$ value from 2.4 to $1.3 \mathrm{Wm}^{-1} \mathrm{~K}^{-1}$. This result indicates that low thermal conductivity is induced from an atomic unbalance of crystal structure owing to the A-site vacancy.

Figure 7 represents the figure of merit $(Z)$ as a function of the $\mathrm{Nd}$ content. The $Z$ values of $\mathrm{Ca}_{1-x} \mathrm{Nd}_{2 x / 3} \square_{x / 3} \mathrm{MnO}_{3}$ were larger than those of $\mathrm{Ca}_{1-x} \mathrm{Nd}_{x} \mathrm{MnO}_{3}$ and the reason for this is likely because the insertion of the A-site vacancy decreases the thermal conductivity while it simultaneously increases the electrical conductivity. We considered that the insertion of an A-site vacancy into Perovskite-type structure could improve the figure of merit by decreasing the thermal conductivity and the increasing power factor $\left(S^{2} \sigma\right)$. Consequently, we obtained the maximum figure of merit $Z=0.19 \times 10^{-3} \mathrm{~K}^{-1}$, at $873 \mathrm{~K}$. Thus, the insertion of A-site vacancy into the Perovskite-type structure could be an improved method to enhance thermoelectric performance.

\section{Conclusion}

The orthorhombic perovskite-type oxide systems, $\mathrm{Ca}_{1-x} \mathrm{Nd}_{x} \mathrm{MnO}_{3}$ and $\mathrm{Ca}_{1-x} \mathrm{Nd}_{2 x / 3} \square_{x / 3} \mathrm{MnO}_{3}$ ( $\square$ indicates A-site vacancy) were synthesized by a standard ceramic technique. The primitive-lattice parameters revealed that the insertion of an A-site vacancy induced a crystal structural shift from orthorhombic $\left(a^{\prime}>b^{\prime}>c^{\prime}\right)$ to pseudo-tetragonal $\left(a^{\prime}>b^{\prime}=c^{\prime}\right)$. Rietveld analysis implied that A-site vacancies existed on the $\mathrm{Ca}_{1-x} \mathrm{Nd}_{2 x / 3} \square_{x / 3} \mathrm{MnO}_{3}$ system. The decrease in the absolute Seebeck coefficient of both $\mathrm{Ca}_{1-x} \mathrm{Nd}_{x} \mathrm{MnO}_{3}$ and $\mathrm{Ca}_{1-x} \mathrm{Nd}_{2 x / 3} \square_{x / 3} \mathrm{MnO}_{3}$ systems likely originate from the increase in carrier concentration owing to the occurrence of $\mathrm{Mn}^{3+}$ when substitution of $\mathrm{Nd}^{3+}$ into $\mathrm{Ca}^{2+}$ site. The electrical conductivity of the $\mathrm{Ca}_{1-x} \mathrm{Nd}_{2 x / 3} \square_{x / 3} \mathrm{MnO}_{3}$ system is larger than that of the $\mathrm{Ca}_{1-x} \mathrm{Nd}_{x} \mathrm{MnO}_{3}$ system. Jonker plots reveal that the carrier mobility is increased by the insertion of an A-site vacancy. The increase in the carrier mobility likely originates from change in the crystal- 

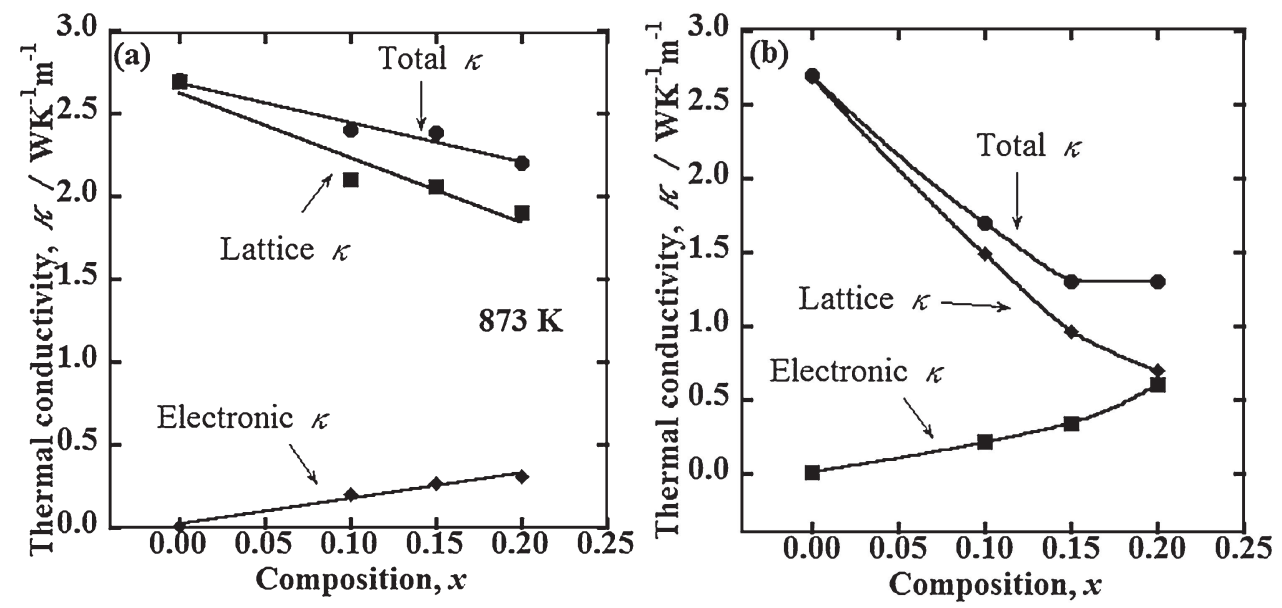

Fig. 6 Thermal conductivity of (a) $\mathrm{Ca}_{1-x} \mathrm{Nd}_{x} \mathrm{MnO}_{3}$ (b) $\mathrm{Ca}_{1-x} \mathrm{Nd}_{2 x / 3} \square_{x / 3} \mathrm{MnO}_{3}$.

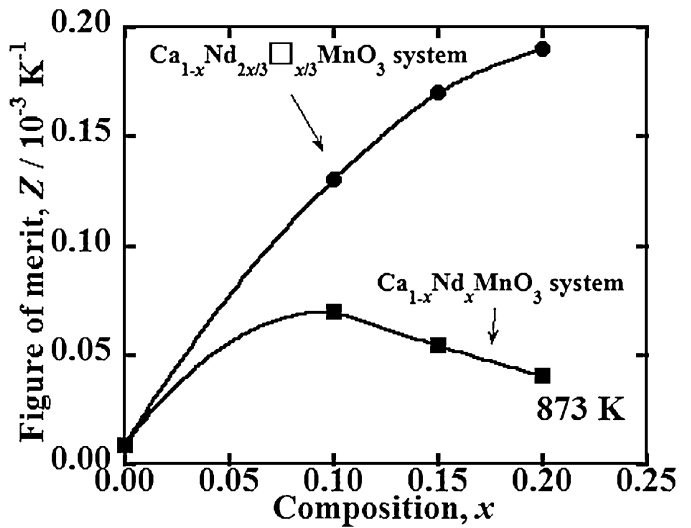

Fig. 7 Figure of merit for $\mathrm{Ca}_{1-x} \mathrm{Nd}_{x} \mathrm{MnO}_{3}$ and $\mathrm{Ca}_{1-x} \mathrm{Nd}_{2 x / 3} \square_{x / 3} \mathrm{MnO}_{3}$ systems.

symmetry. The insertion of A-site vacancy into the Perovskite-type structure lowered the thermal conductivity, likely induced by an atomic unbalance of crystal structure. We obtained the maximum figure of merit $Z=0.19 \times$ $10^{-3} \mathrm{~K}^{-1}$ at $873 \mathrm{~K}$. The insertion of A-site vacancies is important for obtaining higher electrical conductivity and lower thermal conductivity.

\section{Acknowledgment}

This study was supported by Scientific Frontier Research Project of the Ministry of Education, Culture, Sports, Science and Technology, Japan.

\section{REFERENCES}

1) M. Ohtaki, T. Tsubota, K. Eguchi and H. Arai: J. Appl. Phys. 79 (1996) 1816.

2) R. Funahashi, I. Matsubara, H. Ikuta, T. Takeuchi, U. Mizutani and S. Sodeoka: Jpn. J. Appl. Phys. 39 (2000) L1127.

3) R. Funahashi and I. Matsubara: Appl. Phys. Lett. 79 (2001) 362.

4) M. Ohtaki, T. Tokunaga, K. Eguchi and H. Arai: 16th Int. Conf. Thermo. (1997) pp. 224-227.

5) D. Flahaut, T. Mihara and R. Funahashi: J. Appl. Phys. 100 (2006) 084911.

6) G. A. Slack: CRC Handbook of Thermoelectrics, (CRC press, Inc., Boca Raton, 1995) 407-440.

7) H. Kawakami, K. Kakinuma and H. Yamamura: Trans. Mater. Res. Soc. Japan 33 (2008) 1119-1121.

8) H. Kawakami, H. Noda, M. Sugimoto, T. Takayama and H. Yamamura: Trans. Mater. Res. Soc. Japan 34 (2009) 245-248.

9) S. N. Ruddlesden and P. Popper: Acta Crystallogr. 11 (1958) 54.

10) H. Kawakami, M. Anzai, M. Sugimoto, T. Takayama and H. Yamamura: Trans. Mater. Res. Soc. Japan 35 (2010) 499-502.

11) Z. Mu, L. Zhang, X. Li and J. Hu: J. Rare Earths 29 (2011) 374-377.

12) X. Li, H. Zhao, N. Xu, Z. Xie and N. Chen: Int. J. Hydrogen Energy 35 (2010) 7913-7918.

13) L. Latie, G. Villeneuve, D. Conte and G. L. Flem: J. Solid State Chem. 51 (1984) 293.

14) A. G. Belous, G. N. Novitskaya and S. V. Polyanetskaya: Izv. Akad. Nauk SSSR, Neorg. Mater. 23 (1987) 1330.

15) M. Itoh, Y. Inaguma, W. H. Jung, L. Chen and T. Nakamura: Solid State Ionics 70-71 (1994) 203.

16) R. D. Shannon: Acta Crystallogr. A 32 (1976) 751.

17) F. Izumi and K. Momma: Solid State Phenom. 130 (2007) 15-20.

18) M. E. Melo Jorge, A. Correia dos Santos and M. R. Nunes: Int. J. Inorg. Mater. 3 (2001) 915-921.

19) G. H. Jonker: Philips Res. Rep. 23 (1968) 131.

20) Y. Kinemuchi, C. Ito, H. Kaga, T. Aoki and K. Watari: J. Mater. Res. 22 (2007) 1942-1946. 